\title{
CARACTERÍSTICAS FÍSICO-QUÍMICAS DE QUEIJO MINAS ARTESANAL DO SERRO FABRICADOS COM PINGO E COM RALA
}

\section{Physical-chemical characteristics of artisanal Minas cheese of the Serro with pingo and with rala}

\begin{abstract}
Sâmya Petrina Pessoa Oliveira ${ }^{1 *}$, José Manoel Martins ${ }^{l}$, Cristina Henriques Nogueira ${ }^{l}$, Rosana Campos do Vale ${ }^{l}$, Maria Paula Jensen Rodrigues ${ }^{l}$, Aline Nogueira Galleti ${ }^{l}$
\end{abstract}

\section{RESUMO}

A produção do queijo Minas artesanal do Serro é realizada com a utilização do leite cru, coalho e fermento lático natural, conhecido por pingo. Alguns produtores da região fazem uso da rala, parte ralada do próprio queijo artesanal que é adicionado ao leite em substituição ao pingo. O objetivo deste trabalho foi avaliar a influência do tipo de fermento (pingo ou rala) nas características físico-químicas do queijo Minas artesanal do Serro maturado nas fazendas. Queijos artesanais de seis produtores cadastrados no Instituto Mineiro de Agropecuária (IMA) foram maturados nas propriedades de origem durante 31 dias. Os queijos foram analisados nos Laboratórios do Departamento de Ciência e Tecnologia de Alimentos do IF Sudeste MG, Campus Rio Pomba, nos tempos 3, 10, 17, 24 e 31 dias de maturação. Houve diferença $(\mathrm{p}<0,05)$ para tratamento e tempo para os parâmetros de extensão de maturação, profundidade de maturação e $\mathrm{pH}$. Não houve diferença $(\mathrm{p}>0,05)$ entre os tratamentos de queijos fabricados com "pingo" e com rala, para os seguintes parâmetros físicoquímicos: acidez, umidade, proteína, gordura e gordura no extrato seco. Estudos mais aprofundados sobre as condições de maturação dos queijos Minas artesanais deverão ser mais bem explorados para que este produto possa atender não somente aos padrões microbianos, mas principalmente às características sensoriais, que tanto tem atraído à atenção do consumidor.

Palavras-chave: queijo artesanal; fermento endógeno; maturação.

1 Instituto Federal de Educação, Ciência e Tecnologia do Sudeste de Minas Gerais - Campus Rio Pomba, Av. Dr. José Sebastião da Paixão, Lindo Vale, 36180-000, Rio Pomba, MG, Brasil. E-mail: samyapetrina@ hotmail.com.

* Autor para correspondência. 


\begin{abstract}
The production of the Minas artisanal cheese from Serro is carried out using raw milk, rennet and natural lactic ferment known as pingo. Some producers of the region make use of the rala, a grated part of the own artisanal cheese that is added to the milk in substitution for the pingo. The objective of this work was to evaluate the influence of the type of yeast (pingo or rala) on the physical-chemical characteristics of the Minas artisanal cheese from Serro matured on farms. Handmade cheeses from six producers registered at the Minas Gerais Institute of Agriculture (IMA) were matured at the properties of origin for 31 days. The cheeses were analyzed at the Laboratories of the Food Science and Technology Department of the Southeast IF MG, Campus Pomba Campus at times 3, 10, 17, 24 and 31 maturation days. There was a difference $(\mathrm{p}<0.05)$ for treatment and time for maturation extension, maturation depth and $\mathrm{pH}$. There were no differences $(\mathrm{p}>0.05)$ between cheeses made with pingo and with rala, for the following physical and chemical parameters: acidity, moisture, protein, fat and fat in the dry extract. More in-depth studies on the maturation conditions of the Minas artisanal cheeses should be better explored so that this product can meet not only the microbial standards, but mainly the sensorial characteristics, which has attracted so much attention of the consumers.
\end{abstract}

Keywords: artisanal cheese; endogenous yeast; maturation.

\section{INTRODUÇÃO}

A produção de queijos no Brasil tem aumentado gradativamente nos últimos anos com a demanda impulsionada pela elevação do poder aquisitivo da população. Em 2013 ultrapassou um milhão de toneladas (SEBRAE, 2014). Os queijos artesanais, devido à sua singularidade, estão ganhando cada vez mais espaço junto ao comércio de queijos finos no Brasil, atingindo uma classe com poder aquisitivo mais elevado e com maior conhecimento de produtos com qualidade. Trata-se de um queijo que possui valor social de grande relevância, uma vez que suas regiões produtoras são compostas, em sua maioria, por famílias rurais que estão envolvidas diretamente nessa produção, sendo esta, sua principal ou única fonte de renda. Neste contexto, fica evidenciada a importância histórica, cultural e econômica que este produto representa para o estado de Minas Gerais.
Em razão da sua história, tradição e cultura, o Serro é reconhecidamente uma das mais importantes regiões produtoras de queijo artesanal no Brasil. Segundo essa premissa, o Instituto Estadual do Patrimônio Histórico e Artístico de Minas Gerais - IEPHA-MG registrou "o modo de fazer" do queijo Minas artesanal do Serro como "Patrimônio Imaterial de Minas Gerais". Por meio do Decreto $\mathrm{n}^{\mathrm{o}} 42.505$ de 15 de abril de 2002, o IEPHAMG (2002) destaca o potencial econômico do patrimônio preservado e a necessidade de ampliar a consciência sobre a importância dos bens representativos de Minas Gerais, tais como o queijo Minas artesanal (SILVA et al., 2011).

Embora o seu "modo de fazer" seja secular, nos últimos anos, alguns produtores da região do Serro têm substituído um dos seus principais ingredientes, o pingo, pela rala, que é uma fração do queijo ralado e adicionada ao leite no momento da fabricação. A principal justificativa da mudança está 
baseada na melhoria da consistência do queijo, principalmente nos primeiros dias após a fabricação, quando os queijos, mesmo em estações mais frias, conseguem ser comercializados com tempo inferior a cinco dias.

Entretanto, esta mudança tem provocado o questionamento de consumidores e da própria Cooperativa dos Produtores Rurais do Serro em relação às características do produto final. O principal questionamento é que, se com "rala" é mantido o mesmo padrão de qualidade do queijo fabricado com pingo. Assim, o presente trabalho teve como objetivo avaliar a influência do tipo de fermento (pingo e rala) nas características físico-químicas do queijo Minas artesanal do Serro, maturado nas fazendas.

\section{MATERIAL E MÉTODOS}

Queijos artesanais de seis produtores rurais da região do Serro, cadastrados no Instituto Mineiro de Agropecuária (IMA), sendo três (3) fabricados com pingo e três (3) com rala, foram produzidos e maturados nas propriedades de origem (fazendas) durante 31 dias (junho/julho de 2017), respeitando as condições naturais (temperatura e umidade relativa do ar) de cada queijaria.

Considerando os tempos de análises, 3 , 10, 17, 24 e 31 dias de maturação, os queijos artesanais foram coletados diretamente nas propriedades de origem (fazendas), e imediatamente transportados até os laboratórios do Departamento de Ciência e Tecnologia de Alimentos do Instituto Federal de Ciência e Tecnologia do Sudeste de Minas Gerais (IF Sudeste MG), Campus Rio Pomba, para a realização das análises. Uma amostra de cada produtor, em cada tempo, foi analisada quanto às características físico-químicas.

Os queijos artesanais foram submetidos às seguintes determinações: para a determinação da umidade, gordura, acidez titulável e gordura no extrato seco (GES) foram utilizados os métodos oficiais para as referidas análises, descritos na Instrução Normativa $n^{\circ}$ 68, de 12 de dezembro de 2006 (BRASIL, 2006). A determinação de nitrogênio total, nitrogênio solúvel em pH 4,6 e nitrogênio solúvel em ácido tricloroacético 12\% TCA (ácido tricloroacético) foram realizadas de acordo com Silva et al. (1997).

$\mathrm{O}$ teor de proteína total (PT) foi determinado de modo indireto, multiplicando-se a \% de nitrogênio total encontrado (NT) pelo fator de conversão (F) da relação nitrogênio/ proteína, de acordo com a fórmula: $\mathrm{PT}=\mathrm{NT}$ x F. No caso de produtos lácteos, o valor de F é 6,38 (BRASIL, 2006).

O índice de extensão de maturação (IEM) foi calculado de forma indireta, por meio da razão entre a \% de nitrogênio solúvel em pH 4,6 (NS pH 4,6) e o nitrogênio total (NT), multiplicando-se o resultado por 100 , de acordo com a fórmula: IEM $=\mathrm{NS}$ pH 4,6 / NT x 100.

$\mathrm{O}$ índice de profundidade de maturação (IPM) também foi determinado de forma indireta, através da razão entre a $\%$ de nitrogênio solúvel em TCA 12\% (NS TCA $12 \%$ ) e o nitrogênio total (NT), multiplicandose o resultado por 100 , de acordo com a fórmula: IPM = NS TCA $12 \%$ / NT x 100 .

$\mathrm{O}$ experimento foi implementado sob o delineamento inteiramente casualizados (DIC), foi considerado o esquema fatorial $2 \times 5$, sendo dois tratamentos (fermento com "pingo" e fermento com "rala") e cinco tempos de maturação $(3,10,17,24$ e 31 dias). Os dados analisados foram submetidos à análise de variância com o objetivo de verificar os efeitos principais e das interações entre os fatores estudados. Os modelos considerados pressupõem que os erros sejam independentes e identicamente distribuídos, segundo distribuição normal com média zero e variância constante. Foi realizado análise de variância ANOVA e teste de Tuckey com $5 \%$ de significância. 


\section{RESULTADOS E DISCUSSÃO}

Não houve diferença $(p>0,05)$ entre os tratamentos de queijos Minas artesanais fabricados com "pingo" e com "rala", para os seguintes atributos físico-químicos analisados: umidade, acidez titulável, gordura e teor de gordura no extrato seco e proteína. Para os demais parâmetros analisados houve diferença $(\mathrm{p}<0,05)$ para tratamento e tempo, conforme apresentado na Tabela 1 .

De acordo com a Tabela 1, a umidade dos queijos diminuiu $(\mathrm{p}<0,05)$ ao longo do período de maturação, independentemente do tipo de fermento utilizado em sua fabricação. A umidade dos queijos fabricados com pingo ao longo da maturação foi maior para os tempos 03 e 10 dias, quando comparada com os tempos 24 e 31 dias $(\mathrm{p}<0,05)$.

O comportamento da concentração da umidade ao longo do tempo é apresentado na Figura 1. O modelo sugere uma umidade inicial de 53,677\%, de modo que a cada dia de maturação há uma diminuição de 0,813\% dessa umidade. Essa redução da umidade é comum em queijos artesanais e está relacionada com a maturação realizada sem controle de umidade e temperatura. A variação da concentração de umidade está ligada ao tempo de maturação, ao processo de produção, à quantidade e ao tipo de salga, bem como à pressão exercida no momento da prensagem. Sua diminuição pode estar ainda diretamente relacionada à época de

Tabela 1 - Valores médios dos parâmetros físico-químicos de queijos Minas artesanais do Serro fabricados com "pingo" e com "rala", maturados em fazendas

\begin{tabular}{|c|c|c|c|c|c|c|c|}
\hline \multirow{2}{*}{ Parâmetro } & \multirow{2}{*}{$\begin{array}{l}\text { Tipo de } \\
\text { fermento }\end{array}$} & \multicolumn{5}{|c|}{ Período de maturação (dias) } & \multirow{2}{*}{$\begin{array}{c}X \\
\text { fermento }\end{array}$} \\
\hline & & 03 & 10 & 17 & 24 & 31 & \\
\hline Umidade & pingo & $52,05^{\mathrm{Aa}}$ & $47,51^{\mathrm{Aa}}$ & $41,14 \mathrm{Aab}$ & $34,58 \mathrm{Ab}$ & $30,71 \mathrm{Ab}$ & $41,20^{\mathrm{A}}$ \\
\hline$(\%)$ & rala & $51,99^{\text {Аа }}$ & $47,10^{\mathrm{Aba}}$ & $40,34 \mathrm{Acb}$ & $33,30 \mathrm{Ac}$ & $29,75 \mathrm{Ac}$ & $40,50^{\mathrm{A}}$ \\
\hline Acidez & pingo & $0,78^{\mathrm{Aa}}$ & $0,65^{\text {Аa }}$ & $0,63^{\mathrm{Aa}}$ & $0,51^{\mathrm{Aa}}$ & $0,52^{\text {Aa }}$ & $0,62^{\mathrm{A}}$ \\
\hline (\% ácido lático) & rala & $0,78^{\mathrm{Aa}}$ & $0,67^{\mathrm{Aab}}$ & $0,52 \mathrm{Aab}$ & $0,41^{\mathrm{Ab}}$ & $0,45^{\text {Aab }}$ & $0,57^{\mathrm{A}}$ \\
\hline Gordura & pingo & $20,50^{\mathrm{Ab}}$ & $24,67^{\mathrm{Aab}}$ & $26,88^{\text {Aac }}$ & $28,00^{\text {Aac }}$ & $30,67^{\mathrm{Ac}}$ & $26,14^{\mathrm{A}}$ \\
\hline$(\%)$ & rala & $21,42^{\mathrm{Ab}}$ & $25,42^{\text {Aab }}$ & $26,83^{\text {Аa }}$ & $29,17^{\text {Аа }}$ & $30,25^{\text {Аa }}$ & $26,62^{\mathrm{A}}$ \\
\hline GES & pingo & $42,78^{\mathrm{Aa}}$ & $46,98^{\mathrm{Aa}}$ & $45,74^{\mathrm{Aa}}$ & $43,11^{\mathrm{Aa}}$ & $44,32^{\mathrm{Aa}}$ & $44,59^{\mathrm{A}}$ \\
\hline$(\%)$ & rala & $44,40^{\mathrm{Aa}}$ & $48,04^{\mathrm{Aa}}$ & $45,15^{\mathrm{Aa}}$ & $43,87^{\mathrm{Aa}}$ & $43,07^{\mathrm{Aa}}$ & $44,91^{\mathrm{A}}$ \\
\hline Proteína & pingo & $19,82^{\mathrm{Ab}}$ & $22,54^{\text {Aab }}$ & $24,57^{\text {Aab }}$ & $25,97^{\mathrm{Aa}}$ & $27,41^{\mathrm{Aa}}$ & $24,06^{\mathrm{A}}$ \\
\hline$(\%)$ & rala & $19,76^{\mathrm{Ac}}$ & $22,54^{\mathrm{Aab}}$ & $24,75^{\text {Aabc }}$ & $26,49^{\mathrm{Abc}}$ & $28,21^{\mathrm{Aa}}$ & $24,35^{\mathrm{A}}$ \\
\hline IEM & pingo & $11,81^{\mathrm{Ab}}$ & $12,00^{\mathrm{Ab}}$ & $14,94^{\mathrm{Aab}}$ & $17,03^{\mathrm{Aa}}$ & $16,67^{\mathrm{Aa}}$ & $14,49^{\mathrm{A}}$ \\
\hline$(\%)$ & rala & $12,21^{\mathrm{Ab}}$ & $13,04^{\mathrm{Ab}}$ & $18,20^{\mathrm{Ba}}$ & $19,84^{\mathrm{Aa}}$ & $22,08^{\mathrm{Ba}}$ & $17,07^{\mathrm{A}}$ \\
\hline IPM & pingo & $4,78^{\mathrm{Ab}}$ & $5,47^{\text {Aab }}$ & $7,02^{\mathrm{Aa}}$ & $5,28^{\text {Aab }}$ & $6,42^{\text {Aab }}$ & $5,79^{\mathrm{A}}$ \\
\hline$(\%)$ & rala & $4,94^{\mathrm{Ab}}$ & $7,74^{\mathrm{Ba}}$ & $7,68^{\mathrm{Aa}}$ & $8,28^{\mathrm{Ba}}$ & $8,59^{\mathrm{Ba}}$ & $7,45^{\mathrm{B}}$ \\
\hline
\end{tabular}

Médias seguidas pela mesma letra não diferem entre si ao nível de 5\% de significância pelo teste de Tukey. As letras minúsculas comparam os períodos de maturação, enquanto as letras maiúsculas comparam os tipos de fermento. GES = gordura no extrato seco; IEM= índice de extensão de maturação; IPM= índice de profundidade de maturação; $X=$ média aritmética. 
realização das análises que foram no período da seca.

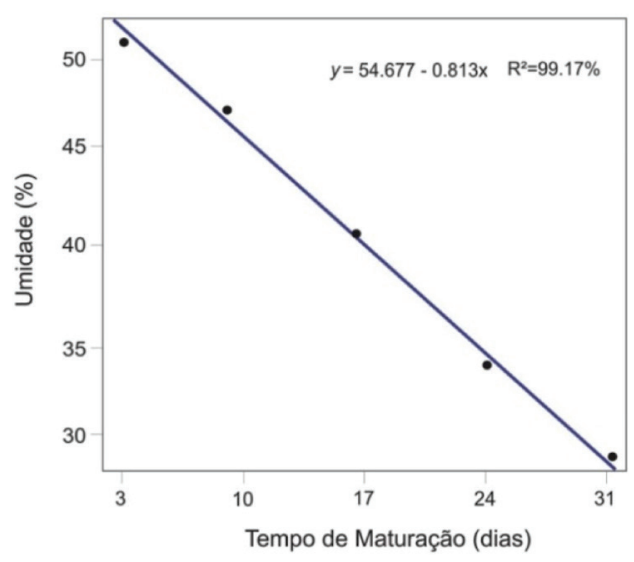

Figura 1 - Estimativa do teor médio de umidade de queijos Minas artesanais da região do Serro fabricados com pingo e rala ao longo do período de maturação (dias)

Nasser et al. (2017), ao analisarem queijo Minas artesanal no município de Rio Paranaíba (região do Cerrado), observaram que todas as amostras analisadas estavam com umidade acima de 45,9\% (máximo permitido após a maturação). Esses resultados corroboram com os valores obtidos neste experimento nas duas primeiras semanas de maturação.

Pinto et al. (2016) ao analisarem queijos artesanal da microrregião de Montes Claros, obteve um teor médio de umidade de $48,05 \%$. Fernandes et al. (2011) ao estudarem queijos Minas artesanais, comercializados na cidade de Rio Paranaíba-MG, obtiveram valores elevados, para umidade que variaram entre $49,1 \%$ e $59,7 \%$, sendo o valor médio de $54,3 \%$.

As médias de acidez titulável encontradas nesse estudo para os queijos Minas artesanal fabricados com "pingo" e com "rala" foram de $0,62 \%$ e $0,57 \%$ de ácido lático, respectivamente, não havendo diferença $(p>0,05)$ entre os tratamentos. Conforme apresentado na Figura 2, a acidez titulável dos queijos Minas artesanais fabricados com "rala" diminuiu $(\mathrm{p}<0,05)$ ao longo do período de maturação. A principal justificativa da mudança está baseada na melhoria da consistência do queijo, principalmente nos primeiros dias após a fabricação, quando os queijos, mesmo em estações mais frias conseguem ser comercializados com tempo inferior a cinco dias. Para os queijos fabricados com "pingo" a diminuição da acidez titulável não foi observada.

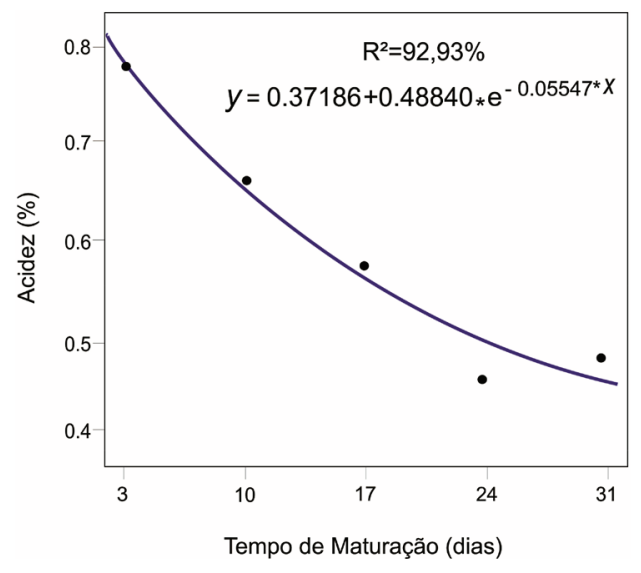

Figura 2 - Estimativa do teor médio de acidez de queijos Minas artesanais da região do Serro fabricados com rala ao longo do período de maturação (dias)

Os valores de acidez normalmente encontrados nos queijos da região do Serro, fabricados com "pingo" e com "rala", tendem a aumentar ao longo do período de maturação devido fermentação da lactose por bactérias "starters" ou fermentadoras (MARTINS, et al. 2015; BRUMANO, 2016), no entanto, neste estudo a acidez diminuiu o que pode ser justificado pelo aumento do $\mathrm{pH}$ ao longo do tempo devido a proteólise.

Souza et al. (2014), observaram variação de 0,12 a 1,01\% de acidez titulável para queijos de produção artesanal. Silva et al. (2012) relataram valores com variação de 
0,14 e 1,84\%. Oliveira et al. (2013), ao analisarem queijos artesanais da região do Serro obtiveram um valor de acidez titulável de 0,46\%. Garcia; Penna (2010) encontraram valores baixos de acidez em queijos artesanais, com média de $0,16 \%$, quando comparado ao presente estudo. Ferraz (2016) encontrou valores de acidez titulável em queijos artesanais produzidos na região da Serra da Canastra variando de $0,53 \%$ a 1,0\%.

Essas variações nos valores de acidez de queijos Minas artesanais pode ser influenciada por diversos fatores como: variedade da microbiota presente no leite cru utilizado na fabricação; composição e atividade do pingo utilizado; processo de dessoragem da massa; teor de sal, umidade e atividade da água do queijo, além do estágio de maturação do produto (DORES, 2013).

Para gordura, não foi observada diferença $(p>0,05)$ entre os dois tipos de tratamento (pingo e rala) em queijos Minas artesanais maturados nas fazendas. Durante a maturação, para os queijos fabricados com pingo, houve diferença $(\mathrm{p}<0,05)$ entre os tempos 3, 10 quando comparado aos 31 dias de maturação. Já para os queijos fabricados com a rala houve diferença $(p<0,05)$ entre os tempos 03 e 17 dias de maturação em diante. O teor de gordura variou de $20,50 \%$ a $30,67 \%$ para queijos fabricados com pingo e de $21,42 \%$ a $30,25 \%$ para queijos fabricados com "rala".

Foi observado um aumento do teor de gordura ao longo da maturação, conforme apresentada na Figura 3.

Pelo ajuste ao modelo linear de $1^{\mathrm{o}}$ grau, o teor médio de gordura é $20,906 \%$ com um aumento de $0,322 \%$ a cada dia de maturação. Essa variação nos percentuais de gordura tanto dos queijos fabricados com "pingo", quanto dos queijos fabricados com "rala" pode ser explicada pelo fato da gordura no leite ser o componente mais variável, tendo em vista que é influenciada por diversos fatores: genéticos, ambientais, de manejo e de nutrição animal, implicando assim em variações no teor de lipídios do queijo. Além disso, o aumento na concentração de gordura pode ser justificado em função da perda de umidade, uma vez que no decorrer da maturação a perda de água leva consequentemente, ao aumento na proporção dos constituintes sólidos, entre eles a gordura.

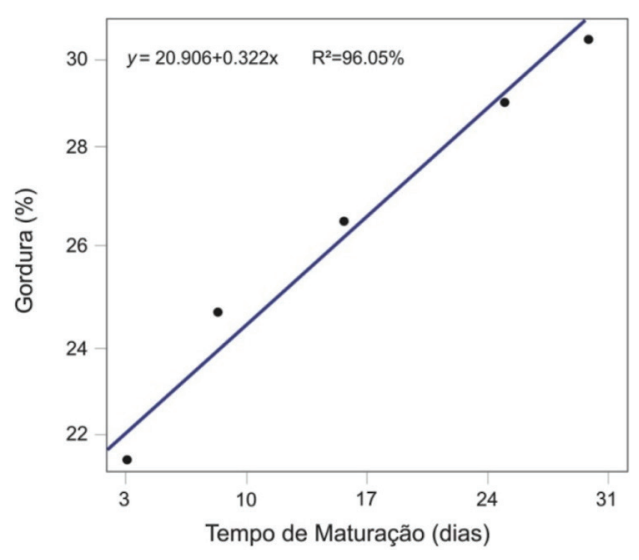

Figura 3 - Estimativa do teor médio de gordura ao longo do período de maturação (dias) de queijos Minas artesanais do Serro fabricados com pingo e com rala

Figueiredo et al. (2015) ao avaliarem amostras de doze produtores de QMA do Serro recém-fabricado (fresco) e com 17 dias de maturação, observaram que a umidade dos queijos diminuiu, em média, $25 \%$, o que gerou um incremento de $17 \%$ no teor de gordura e aumento da firmeza, de modo que com a perda de água, o queijo ficou mais firme e a gordura mais concentrada. Pinto et al. (2016), ao estudarem queijos artesanais da microrregião de Montes Claros, obtiveram um teor médio de gordura de $26,34 \%$.

A gordura é o componente que naturalmente sofre maior variação no leite. O leite utilizado na fabricação de queijo Minas artesanal não sofre nenhum tipo de padronização quanto ao teor de gordura. O teor de gordura do leite é influenciado pela estação 
do ano, devido a variações ocorridas na alimentação animal, estágio de lactação e raça dos animais. O período de maturação dos queijos é outro fator que influencia decisivamente no teor de gordura do produto (FERRAZ, 2016).

Para gordura no extrato seco (GES) não houve diferença $(p>0,05)$ entre os queijos Minas artesanais da região do Serro fabricados com "pingo" e "rala" em nenhum dos tempos analisados. Tanto os queijos fabricados com "pingo" quanto os fabricados com "rala" foram classificados como queijos semigordos durante todo período de maturação, com exceção do tempo 10 dias, quando ambos foram classificados como queijos gordos. A legislação brasileira (BRASIL, 1996) classifica os queijos em desnatados $(<10,0 \%)$, magros (10 a $24,9 \%)$, semigordos $(25,0$ a $44,9 \%)$, gordos $(45,0$ a $59,9 \%)$ e extragordos ou duplo creme $(\geq 60,0 \%)$.

Brumano (2016) obteve valores médios de GES entre $45 \%$ e $59,9 \%$ tanto para queijos fabricados com "rala" como para queijos fabricados com "pingo". Oliveira et al. (2013), ao analisaram queijos artesanais da região do Serro encontraram teor de GES de 52,95\%.

Em relação à proteína não foi observada diferença $(p>0,05)$ entre os dois tipos de fermento (pingo e rala) usados na fabricação dos queijos Minas artesanais, mas houve diferença $(\mathrm{p}<0,05)$ entre o tempo 3 e os tempos 24 e 31 dias de maturação para os queijos fabricados com pingo. Já para os queijos fabricados com a rala houve diferença $(p<0,05)$ entre o tempo 03 e 24 dias de maturação.

O teor de proteína variou de $19,76 \%$ a $27,41 \%$ para queijos fabricados com pingo e de $19,76 \%$ a $28,21 \%$ para queijos fabricados com rala. Foi observado um aumento no conteúdo de proteína ao longo da maturação para os dois tipos de fermentos utilizados, apresentado na Figura 4.

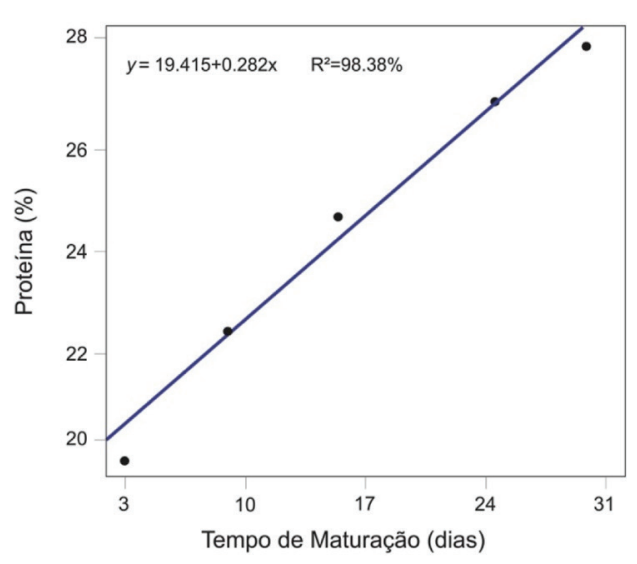

Figura 4 - Estimativa do teor médio de proteína ao longo do período de maturação (dias) de queijos Minas artesanais do Serro fabricados com pingo e rala

Ferraz (2016) obteve resultados similares ao deste estudo para queijos Canastra fabricados com pingo, onde o teor de proteína variou de $22,0 \%$ para $29,2 \%$, entre os tempos 1 e 28 dias de maturação. Pinto et al. (2016), ao analisaram queijos artesanais da microrregião de Montes Claros, encontraram teor médio de proteína de 21,09\%. Martins et al. (2015) também observaram variações no teor de proteína de queijo Minas artesanal da microrregião do Serro entre 27,6 a 37,0\% (período da seca) e 25,2 a 35,3\% (período chuvoso), em queijos fabricados com pingo e maturados à temperatura ambiente entre os tempos 8 a 63 dias.

De acordo com a Figura 5, o índice de extensão de maturação (IEM) apresentou resultados próximos nos primeiros dias de maturação apresentando diferença entre os tratamentos $(\mathrm{p}<0,05)$ nos dias 17 e 31 de maturação. De acordo com Brumano (2016), isso se justifica, pois a microbiota presente na "rala" e consequentemente nos queijos resultou em uma maior degradação dos compostos nitrogenados. 


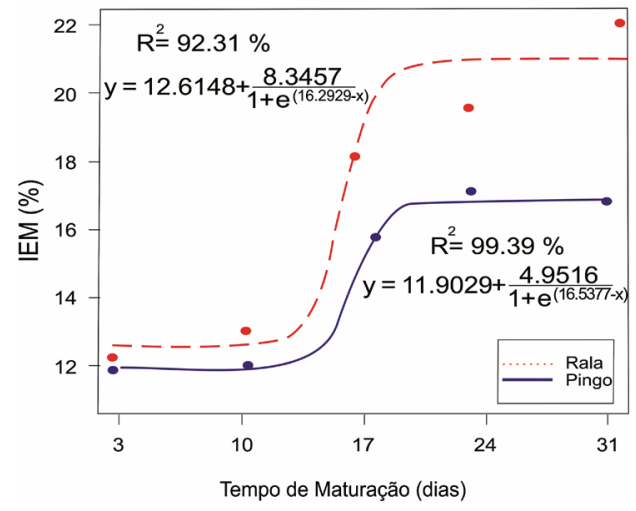

Figura 5 - Estimativa do modelo Logístico não-linear do índice de extensão de maturação para queijos f abricados com pingo e com rala ao longo do período de maturação (dias)

Valores inferiores ao presente estudo foram relatados por vários pesquisadores que avaliaram a degradação proteica de QMA, a fim de conhecer o grau de proteólise deste produto. Ferraz (2016) obteve valores de IEM em queijos artesanais da Serra da Canastra, fabricados com pingo, maturados em Centro de Qualidade entre 5,5\% (01 dia de maturação) e 9,2\% (28 dias de maturação). Pinto et al. (2016), ao analisarem queijos artesanais da microrregião de Montes Claros, obtiveram um teor médio de IEM de 9,88\%. Costa Júnior et al. (2009), avaliando efeitos da maturação de amostras de QMA durante 60 dias, encontraram valores de IEM entre 7,3\% (2 dias de fabricação) e 15,0\% (60 dias de maturação).

$\mathrm{O}$ índice de profundidade de maturação (IPM) foi influenciado $(\mathrm{p}<0,05)$ pelo tempo e pelo tratamento. Queijos fabricados com "pingo" apresentaram menores valores de IPM $(p<0,05)$ nos tempos 10, 24 e 31 dias. Para queijos fabricados com "pingo", somente houve aumento do valor de IPM $(\mathrm{p}<0,05)$ a partir do $17^{\circ}$ dia, quando comparado ao primeiro dia de análise. Já em queijos fabricados com "rala" essa diferença $(\mathrm{p}<0,05)$ já foi observada entre a primeira semana de análise e os demais dias de maturação.

Na rala, não se sabe se as bactérias predominantemente presentes eram capazes de produzir endopeptidases e exopeptidases responsáveis pela proteólise adequada dos queijos. Ao contrário, o pingo apresenta um balanceamento adequado de bactérias do ácido lático e outras bactérias, que vão se adaptando ao meio e criando condições que estimulam a diminuição de algumas espécies, enquanto outras começam a predominar. Isso gera um ecossistema complexo responsável, inclusive, pelas características sensoriais peculiares desses queijos (DORES; FERREIRA, 2012; MONTEL, 2014; BRUMANO, 2016).

Além da atividade das bactérias lácteas, outro fator que pode ter contribuído para o aumento do IPM dos queijos maturados na propriedade é a complexidade da microbiota presente nas queijarias, seja no ambiente ou nos utensílios e materiais que entram em contato com a superfície dos queijos. Um bom exemplo são as prateleiras utilizadas para a maturação dos queijos, que apresentam visualmente a formação de pedras de leite e possível presença de biofilmes (FERRAZ, 2016).

\section{CONCLUSÕES}

Os queijos Minas artesanais do Serro fabricados com pingo não diferiram dos queijos fabricados com rala em relação às características físico-químicas, com exceção do índice de extensão de maturação (IEM) e do índice de profundidade de maturação (IPM).

O tempo influenciou na redução da umidade e consequentemente no aumento do teor de gordura e de proteína dos queijos Minas artesanais do Serro, independentemente do tipo de fermento.

Estudos mais aprofundados sobre as condições de maturação dos queijos Minas 
artesanais deverão ser mais bem explorados para que este produto possa atender não somente aos padrões microbianos, mas principalmente às características sensoriais, que tanto tem atraído à atenção do consumidor.

\section{REFERÊNCIAS}

BRASIL. Ministério da Agricultura, Pecuária e Abastecimento. Instrução Normativa $\mathrm{n}^{\mathrm{o}} 68$, de 12 de dezembro de 2006. Oficializa os métodos analíticos oficiais físico-químicos, para controle de leite e produtos lácteos. Diário Oficial da República Federativa do Brasil, Brasília, 14 dez. 2006. Seção 1, p. 8.

BRASIL. Ministério da Agricultura, Pecuária e Abastecimento. Portaria $n^{\circ} 146$, de 7 de março de 1996. Aprova os regulamentos técnicos de identidade e qualidade dos produtos lácteos. Diário Oficial da República Federativa do Brasil, Brasília, 11 mar. 1996. Seção 1, p. 3977.

BRUMANO, E. C. D. C. Impacto do tipo de fermento endógeno na qualidade e tempo de maturação de queijo Minas artesanal produzido em propriedades cadastradas pelo IMA (Instituto Mineiro de Agropecuária) na região do Serro-MG. 2016. 136 f. Tese (Doutorado em Ciência e Tecnologia de Alimentos) - Universidade Federal de Viçosa, Viçosa. 2016.

COSTA JÚNIOR, L. C. G. et al. Variações na composição de queijo Minas artesanal da Serra da Canastra nas quatro estações do ano. Revista do Instituto de Laticínios Cândido Tostes, v. 64, n. 371, p. 13-20, 2009.

DORES, M. T.; FERREIRA, C. L. L. F. Queijo Minas Artesanal, tradição centenária: ameaças e desafios. Revista Brasileira de Agroecologia e Desenvolvimento Sustentável, v. 2, p. 26-34, 2012.
DORES, M. T. Enterotoxigenidade de Staphylococcus aureus isolados de queijo Minas artesanal da Canastra. 2013. $78 \mathrm{f}$. Tese (Doutorado em Ciência e Tecnologia de Alimentos) - Universidade Federal de Viçosa, Viçosa, 2013.

FERNANDES, R. V. B. et al. Avaliação Físico-Química, Microbiológica e Microscópica Do Queijo Artesanal Comercializado Em Rio Paranaíba-MG. Revista do Instituto de Laticínios Cândido Tostes, v. 66, n. 382, p. 21-26, 2011 .

FERRAZ, W. M. Queijo Minas artesanal da Serra da Canastra: influência do ambiente sobre a maturação. 2016. 93p. Dissertação (Mestrado em Ciência e Tecnologia de Alimentos). Instituto Federal de Educação, Ciência e Tecnologia do Sudeste de Minas Gerais- Campus Rio Pomba, Minas Gerais.

FIGUEIREDO, S. P. et al. Características do leite cru e do queijo minas artesanal do Serro em diferentes meses. Archives of Veterinary Science, v. 20, n. 1, p. 68-81, 2015.

GARCIA, G. A. C.; PENNA, A. L. B. Reduced fat prato cheese added of proteolytic enzyme: physical and sensorial characteristics. Revista Instituto Adolfo Lutz, v. 69, n. 3, p. 346-357, 2010.

INSTITUTO ESTADUAL DO PATRIMÔNIO HISTÓRICO E ARTÍSTICO DE MINAS GERAIS (IEPHA). Decreto ${ }^{\circ} 42.505$, de 15 de abril de 2002. Registro de bens culturais de natureza imaterial ou intangível que constituem patrimônio cultural de Minas Gerais. Diário Oficial, Belo Horizonte, 2002.

MARTINS, J. M. et al. Determining the minimum ripening time at room temperature and under refrigeration of Minas artisanal cheese, a traditional Brazilian cheese. 
Brazilian. Journal of Microbiology, v. 46, n. 1, p. 219-230, 2015.

MONTEL, M. C. et al. Traditional cheeses: Rich and diverse microbiota with associated benefits, International Journal of Food Microbiology, v. 177, p. 136-154, 2014.

NASSER, V. G. et al. A microbiological and physical-chemical based evaluation of artisanal minas cheese production in Rio Paranaíba City, Minas Gerais, Brazil. Avaliação microbiológica e físico-química na elaboração de queijo minas artesanal no município de Rio Paranaíba, Minas Gerais. Revista Acadêmica: Ciência Animal, v. 14, n. 13, p. 47-56, 2017.

OLIVEIRA, D. F. et al. Caracterização físico-química de queijos Minas artesanal produzidos em diferentes microrregiões de Minas Gerais. Revista Brasileira de Economia Doméstica, v. 24, n. 2, p. 185-196, 2013.

PINTO, M. S. et al. Características físicoquímicas e microbiológicas do queijo artesanal produzido na microrregião de Montes
Claros-MG. Revista do Instituto de Laticínios Cândido Tostes, v. 71, n. 1, p. 43-52, 2016.

SEBRAE. Queijos nacionais (Estudo de Mercado). Brasil: ESPM, 2014.

SILVA, N. C.; TUNES, R. M. M.; CUNHA, M. F. Avaliação química de queijos Minas artesanais frescos e curados em Uberaba, MG. PUBVET, v. 6, n. 16, Edição. 203, Art. 1358, 2012.

SILVA, J. G. et al.Características físicoquímicas do queijo Minas artesanal da Canastra. Revista do Instituto Laticínios Cândido Tostes, v. 66, n. 380, p. 16-22, 2011.

SILVA, P. H. F. et al. Físico-química do leite e derivados - Métodos analíticos, Juiz de Fora: Oficina de Impressão Gráfica e Editora, $1997.190 \mathrm{p}$.

SOUZA, B. L. et al. Pesquisa de Staphylococcus Aureus em Amostras de Queijo Minas Artesanal. Blucher Food Science Proceedings, v. 1, n. 1, p. 379-380, 2014. 